\title{
Erratum to: Differential Ion Mobility Separations in up to $100 \%$ Helium Using Microchips
}

\author{
Alexandre A. Shvartsburg, Yehia M. Ibrahim, Richard D. Smith \\ Biological Sciences Division, Pacific Northwest National Laboratory, P.O. Box 999, Richland, WA 99352, USA
}

Published Online: 26 August 2014

Erratum to J. Am Soc. Mass Spectrom.

DOI: 10.1007/s13361-013-0797-4

Inaccurate grant information was shown in our recently published article. The correct acknowledgment is shown below. The authors regret this error.

\section{Acknowledgments}

The authors thank Owlstone for providing their FAIMS stages, Dr. Keqi Tang, Ronald Moore, Karl Weitz, and Dr. Danielle Toutoungi for major experimental help, Dr. Giorgis Mezengie for the lipid sample, Professor Helen Cooper (University of Birmingham, UK) for the phosphopeptide sample, and Bruce Harrer for useful discussions. This work was supported in part by the PNNL Technology Assistance Program, PNNL Technology Commercialization Office, NIGMS (8 P41 GM103493-10 and R21 GM103497-03), and the USDOE OBER, and carried out in the Environmental Molecular Sciences Laboratory, a DOE national scientific user facility at PNNL.

The online version of the original article can be found at http:// dx.doi.org/10.1007/s13361-013-0797-4. 